\title{
CHALLENGES TO COMMUNITY PARTICIPATION IN HERITAGE TOURISM DEVELOPMENT: CASE STUDIES OF SHAHJAHANABAD AND NIZAMUDDIN BASTI IN NEW DELHI, INDIA
}

\author{
EKTA CHAUHAN \\ Brandenburg Technical University, Germany
}

\begin{abstract}
In new Delhi, the capital of India, history and modernity exist side by side, making it an ideal tourist destination. The city is home to three UNESCO world heritage sites, 174 monuments of national importance and thousands of unlisted monuments. These sites exist not in isolation but are living heritage, where communities not only live around the structures but have made the structures part and parcel of their daily lives. Thus, tourism's impacts are most apparent at the level of the destination community and therefore it is essential to decentralize tourism development and policymaking. There is a need to integrate tourism development into the overall community-defined development goals, as is the case with several other developing nations, decision making is highly centralized in India and in Delhi, which results in low level of community participation, mostly at a coercive level and never at a consultative level. This research would, therefore, explore (a) local residents' perception of their role in tourism decision making and (b) barriers in the participation of local communities. The research was carried out through two case studies in Delhi: Nizamuddin Basti and Shahjahanabad. These areas are historically important and are the top tourist destinations for the city. The local condition of tourism development and community involvement, however, vary widely among them, making them ideal for the study. The study adopted a qualitative approach and used field observation and interviews to collect relevant data.
\end{abstract}

Keywords: community participation, cultural heritage tourism, sustainable tourism, participatory policy making.

\section{INTRODUCTION}

Cultural heritage has acquired a new dimension as a result of the recognition that the things it deals with, tangible or intangible, are beyond academic discourse. Cultural heritage provides emotional and intellectual support for communities which in turn helps them to establish their identity. If looked at as a driver of an individual or a community's destiny, heritage management must engage the people. There is a growing need, especially in developing countries, to recognise people's opinions and create more just processes in heritage management in order to provide for social sustainability as well as protect the relationship between people and heritage. Community participation thus becomes critical to the ethical performance of cultural heritage management [1].

While tourism is only one of the many functions of heritage, it has come to occupy a dominant role especially in economic terms as the world's largest and fastest growing industry. Tourism generates $10.4 \%$ of the global GDP and supports nearly 1 in 10 jobs [2]. As a result, tourism has also emerged as a crucial factor in planning and management of historic sites and landscapes. Potentially, tourism industry can play an important role in deciding the fate of the landscape as well the local community. Tourism, if managed sustainably, can make substantial contribution to poverty alleviation, conservation of the natural and cultural heritage, and to overall sustainable development [3]. This is especially the case in developing nations such as India, where natural resources and landscapes are 
abundant and relatively unexplored and where other activities have limited potential for sustainable socio-economic development.

As is the case with several other developing nations, decision making is highly centralised in India, and in the capital Delhi, which results in low level of community participation, mostly at a coercive level and never at a consultative level. The impact of tourism is felt directly and most intensely by the local communities. It has been argued that local communities must be involved in planning and management of tourism as they are best positioned to understand the tourism products associated with their social conditions and local culture. The knowledge of local tourism offerings and appropriateness to local situations signify host communities' involvement in tourism development [4]. In 1966, the World Bank classified the benefits of community participation in tourism into five types: enhancing insight, increasing commitment, improving ability, increasing resources, and social learning [5]. Hence there is a need to meaningfully engage local community in the decision making and planning of tourism process to maintain the right balance between the needs of all the stakeholders for long-term sustainable development of the historical sites and its surroundings.

Despite the agreement over importance of community participation in heritage tourism planning, there is a lacuna in knowledge especially in context in India. While there is an agreement that local stakeholders should be involved in decision making, there seems to be a limited understanding about the existing barriers that prevent the communities from taking part in the decision-making process. This paper would be looking at two heritage tourism hubs in New Delhi with the aim to (a) understand attitude of people towards cultural heritage tourism and (b) identify barriers to participation of local community in cultural heritage tourism management. This paper hopes to bridge this gap in academic research as well as assist policymakers in designing an appropriate framework for meaningfully enhancing participation of local communities.

\section{LITERATURE REVIEW}

\subsection{Sustainable tourism}

With the shift of development discourse towards sustainable development, studies have also started highlighting the concept of sustainable tourism with a focus on aspects such as harmful effects of mass tourism on resources of the local community (natural, built and socio-economic), role of tourism in promoting economic wellbeing, preserving natural and socio-cultural capital and achieving inter and intergenerational equity in benefits and costs of tourism [6]. Sustainability implies judicial use and resilience over time, so sustainable tourism would include optimum use of resources, including biological diversity; minimization of ecological, cultural and social impacts; and maximization of benefits for conservation and local communities. Sustainability also reflects the management structures that are needed to achieve the above. It is in the context of sustainable tourism that one has to view community participation.

People might travel for a wide range of attractions and pleasures and cultural heritage is one among many. Cultural heritage tourism or CHT has thus emerged an important segment of tourism industry that requires special attention due to its peculiar nature and resources. For the purpose of this study, the author would be using the following definition of CHT : CHT is the "movement of persons to cultural attractions in cities in countries other than their normal place of residence, with the intention to gather new information and experiences to satisfy their cultural needs and all movements of persons to specific cultural attractions, such 
as heritage sites, artistic and cultural manifestations, arts and drama to cities outside their normal country of residence" [7].

\subsection{Community participation in CHT}

Research has well established benefits of community participation in heritage and tourism management. There is, however, no overarching definition of "community" and the term is defined depending on the context. The World Heritage Convention promulgated by UNESCO in 1972 recognized cultural heritage as "a function in the life of the community" and the protection of World Heritage "is the duty of the international community as a whole to co-operate" [8]. The Council of Europe uses the term "community" to refer to people who "value specific aspects of cultural heritage which they wish, within the framework of public action, to sustain and transmit to future generation" [9]. It can be further said that people do not need to be in geographical proximity (of each other and the heritage) in order to form the community but should hold similar value towards the heritage resource and share a common goal and vision for its development [1].

There is a need for communities to be involved in local decision making especially for tourism as communities are deeply impacted by both positive and negative impacts of tourism [10]. Snyman argued that tourism should be community driven, where locals take the responsibility to control tourism infrastructures and facilities [11]. According to Haywood, "Healthy, thriving communities are the touchstone for a successful tourism industry". However, financial benefits and activities generated through tourism may not be compatible with a community's other social and economic objectives [12]. In fact the purely economic rationale of tourism development has been challenged and there is a demand for more responsive and community sensitive tourism [13].

There has been a discernible shift in the outlook for policy makers after the Earth Summit 1992. The declaration, Agenda 21, signed by 172 nations, endorsed "sustainable development", has since then become a guiding principle for planning process across the globe. Agenda 21, especially chapter 28, endorses a central role for local agencies in addressing sustainable development issues. Agenda 21 asks local authorities to adopt new ways of designing and implementing policies to adopt key ideas of sustainable development as well as incorporate a collaborative and democratic process of decision making actively involving the local communities [14]. Despite the fact that Agenda 21 makes only a scarce reference to tourism, its significance for tourism industry cannot be ignored.

\subsection{Barriers in community participation for tourism}

A number of barriers may exist that does not allow for realisation of full potential of community participation in tourism management:

\subsubsection{Bureaucracy}

A number of agencies from national to local levels are involved in tourism management. As tourism also directly impacts other sectors of the economy, there might be overlap and conflict of interests between different agencies as well.

\subsubsection{Tourism planning is ad-hoc or absent}

City level plans often do not even mention tourism as a separate activity and therefore do not put forward a strategic and integrated plan for its management. Tourism is seen as a purely commercial activity and collective action of private players (such as hotels, business, conventions) are considered enough. 
2.3.3 Public participation may be seen as unnecessary, time consuming and utopian There is no doubt that decentralised tourism management would accrue significant financial and executive costs. Executive class will have to dilute its own power, interact with citizens, educate them, and take on the danger of failure or bad publicity. These costs look significant at least in the short run

\subsubsection{Conflict between profit motive and social goals}

The tourism industry often may attempt to thwart any attempts that tries to incorporate social and environmental objectives as it is viewed as irrelevant or anti profit.

\subsection{Knowledge gap}

An understanding and knowledge gap exist between the government and community. Communities would require help in establishing a role for themselves which might be unavailable [12].

Tosun argues that while it is now established that community should be involved in development decision making and that currently there is only limited success of community participation, there has been no consensus as to what the reasons for this are. He, therefore, puts forwards three non-exclusive reasons for limitations to community participation in Tourism Development Process (TDP) in developing nations [15]. A summary of Tosun's three limitations are shown in Table 1.

\section{METHODOLOGY}

This research was carried out through qualitative interviews and field observation in the two case study areas. Social science researches have come to rely on case study approach increasingly and it has been recognised as an effective research strategy [16]. Using such an approach allowed to simultaneously consider multiple factors that influenced different community members such as individuals, family, organisations etc. in the selected case areas [17]. Given the complex nature of the research problem and multiplicity of actors and factors involved, case study approach was considered the best suited tool for this research.

A qualitative research methodology was chosen as it allowed the researcher to gather rich information from descriptive data sources such a government reports, archives etc. and from primary sources such as interviews and observation. By using less structured tools such as open-ended interviews and discussions, the participants were given the opportunity to come up with new ideas and build upon the researcher's knowledge rather than be restricted to pre-determined responses. The following two tools were used to gather primary data.

\subsection{Participant observation}

Participant observation has been used in a variety of social science disciplines as a tool for collecting qualitative data about people, process and cultures. For the purpose of this research, such an observation and participation enabled the researcher to study people and their activities and opinions in their natural settings.

\subsection{Semi-structured interviews}

Semi structured interviews were conducted using a-priori structuring of groups with theoretical sampling within the group to determine which case to integrate next. Thus, the structure of the groups to be interviewed was defined in advance by the researcher with a view of delimiting the totality of cases in such a way that all the cases can be integrated into 
the research [18]. Further to make each of the group representative, theoretical sampling as developed by Glaser and Strauss was used instead of statistical sampling. In theoretical sampling the process of data collection is controlled by the emerging theory. Thus, the data was simultaneously collected, coded and analysed to decide which data should be collected next and who should be interviewed. Sampling decisions were made in favour of individuals (or groups of individuals) who could promise to provide greatest insights in light of the material already used and knowledge drawn from it [19].

The research was carried out between December 2019 and February 2020. Several trips to research sites were made and meetings were held the with local community members which helped the researcher to realize the reasons behind community non-participation in tourism development. A list of questions was then prepared around the study theme for the interview script. In total, 47 in-depth interviews were completed.

Each interview was 35-45 minutes in length. All Interviews were recorded with the consent and later transcribed. Interviews were conducted in Hindi and English. Most of the local community members felt more comfortable and confident in Hindi and this ensured better expression and thus authenticity of the data. For internal consistency, interview responses were translated into the English language. Themes, sub-themes, and quotes were analysed to accomplish research objectives of the study. Reliability was attained using an interview script and matching data with field notes.

Table 1: Limitations to community participation in tourism management.

\begin{tabular}{|l|l|}
\hline \multirow{4}{*}{ Operational limitations } & Centralisation of public administration of tourism \\
\cline { 2 - 3 } & Lack of coordination among responsible authorities \\
\cline { 2 - 3 } & Lack of information \\
\hline \multirow{4}{*}{ tructural limitations } & Attitude of professionals \\
\cline { 2 - 2 } & Lack of expertise \\
\cline { 2 - 2 } & Elite domination \\
\cline { 2 - 2 } & Lack of appropriate legal system \\
\cline { 2 - 2 } & Lack of trained human resources \\
\cline { 2 - 2 } & Lack of financial resources \\
\cline { 2 - 2 } & Relatively high cost of public participation \\
\hline \multirow{2}{*}{ Cultural limitations } & Limited capacity of poor people \\
\cline { 2 - 2 } & Apathy/low level of awareness in the community \\
\hline
\end{tabular}

\section{GEOGRAPHICAL SCOPE OF THE STUDY}

This study adopts a case study approach and will be looking at two heritage tourism areas on New Delhi, India. While both the areas receive high number of domestic and international tourists every year, their conditions are vastly different which makes them ideal for a such a study. Though the findings of this study are limited to the case studies, they can be used to understand similar communities in other developing nations.

\subsection{Nizamuddin Basti}

Nizamuddin Heritage Precinct centres around the UNESCO World Heritage Site Humayun's Tomb along with the Hazrat Nizamuddin Basti and Sunder Nursery. The area is densely populated and is a tourist hotspot in the city. The Basti had 1500 households as of 2015 and a large floating population of tourists [20]. Along with Humayun's tomb which attracts domestic and international tourist, the area also houses the Dargah (shrine) of Saint Hazrat 
Nizamuddin which is visited by pilgrims in high number. The area had however, fallen into decay in recent years. However, the situation improved once again with the launch of the Nizamuddin Urban Renewal Project in 2007 as a non-profit Public-Private Partnership between Aga Khan Trust for Culture and multiple government agencies that included the Archaeological Survey of India, Central Public Works Department and the Municipal Corporation of Delhi. The project was unique in its approach of combining heritage conservation with environmental and socio-economic development while working with local communities and stakeholders.

\subsection{Shahjahanabad}

Shahjahanabad or the Walled City of Old Delhi was founded by Mughal Emperor Shah Jahan in 1639. While the city survives even after 350 years, it is now reduced to a fraction of its original grandeur. Along with the UNESCO World Heritage Site Red Fort and Jama Masjid, the area is also home to several other monuments and structures along with a vibrant residential and commercial community. The area has transformed from a royal capital to a wholesale market with dense housing and depilated infrastructure. Despite this, it records a high number of tourist footfall every year; the Red Fort alone attracted 3.6 million visitors in 2018-2019 [21].

Shahjahanabad was also identified by Government of National Capital Region of Delhi to be nominated for inscription as UNESCO's list of World Heritage Cities (the nomination was later withdrawn due to political reasons but nevertheless highlight the importance of the area as a prime tourist location). Shahjahanabad future largely depends on its socio-economic revival and considering its history, the area's natural comparative advantage lies in sustainable cultural tourism. The essential precondition to the revitalisation effort requires a consensus among all stakeholders regarding the basic parameters under which Shahjahanabad is to be redeveloped [22].

\section{FINDINGS}

\subsection{Institutional barriers}

Given the current governance structure of heritage and tourism, local people had very few avenues to engage with the government and express their opinions. There are multiple agencies and jurisdictions involved in the management of heritage and tourism which leads to organisational obstacles. Even in cases where they were invited for public meetings and programs, there was no follow up. For example, even though a workshop for heritage homeowners in Shahjahanabad was organised by the North Delhi Municipal Corporation (NDMC) and Shahjahanabad Redevelopment Corporation (SRDC) [23], there was no follow up to ensure that residents' concerns raised during the meetings were addressed or that owners implemented the suggestions for the upkeep for their property. Such a lack of communication between the community and administrative bodies creates a feeling of mistrust among people which discourages them from participating in any future initiatives [24]. Another major barrier was the power disparities within the community. Marginalised and at-risk groups such as the poor, women, religious minorities and sexual minorities seldom got a chance to put forward their views. A section of the people also felt uncertain that their voices would be heard at all in the development process.

However, local residents of Nizamuddin Basti area were slightly more confident about their role in the development process. Aga Khan Foundation has been engaged in urban 
renewal and heritage management since 2007 in the locality. Community empowerment and consultation form an integral part of the project. Several local community-based groups now function in the Basti that allow people to engage with important issues such as health, education, sanitation and heritage management. To encourage local residents to contribute meaningfully towards tourism development self-help groups such as Insha-e-Noor and Sair-e-Nizamuddin were created. While the former engages women to produce and sell handicraft items, the latter trains youth as guides. This has successfully engaged locals as well as created a feeling of mutual trust among locals and administrative agencies.

\subsection{Lack of awareness}

It was observed that while most participants expressed a desire to be more intimately involved in decision making with the government, they did not know the ways to do so. One of the woman participant for Nizamuddin Basti said, "of course, we will go for whatever meetings the government call us for. It would ultimately affect us. I am sure I can manage household chores and the meeting". While such enthusiasm was welcoming, most of the participants did not know how to engage with the administration. There was a lack of knowledge regarding rights of citizens, governance, administrative laws and judicial system. They felt that local agencies should organise awareness and education drives.

There was also a lack of knowledge regarding the long-term impacts of tourism on local economy and society. While participants were eager to showcase their local culture to tourists, especially foreigners, they did not know the positive or negative impact that might accrue. A resident of Shahjahanabad said, "the level of awareness regarding heritage and tourism is very low. People know that tourists come here, appreciate the local heritage and buy local products. I don't think anyone understand how this affects their life".

\subsection{Limited capacity}

A local of Shahjahanabad said that the community still looks at tourism as a secondary activity for the area rather than the economic mainstay. He pointed out that the area is a now a bustling commercial centre with high rent and in such conditions, no one is willing to restore his property for tourists. It was observed that only limited opportunities were available for the locals to provide services such as accommodation, transport services, tour guiding, eateries and restaurants, entertainment, and souvenir shops, which were not optimally exploited because locals were not trained and lacked the capacity to fully benefit from the activity.

It was also observed that there was a lack of capacity on part of the public bodies in terms of expertise, financial resources and organisational structure. As Tosun had pointed out in his work, administrative bodies in developing nations might not want to spend their limited resources on organising community participation whose benefits appear to be long drawn [15]. This is a major challenge faced in encouraging any community participation in decisions making especially for nations like India with a large and diverse population. The entire exercise of community participation from identifying stakeholders to actually including their suggestions in policies might take months of bureaucratic work as well as financial resources. This further discourages any innovation in the decision-making process.

\subsection{Cultural limitations}

Decision making is typically seen as the realm of the government and not people. Despite a democratic system of governance, community's understanding of democracy is limited to 
their voting rights. As most of the community members were also poor and socially marginalised, there was a fear that "interrupting" the system would be used against them in the future by the authorities. There was also a belief among people that authorities are best suited to make decisions and therefore common folk should not interfere with their working.

Despite an overall enthusiastic attitude towards tourism for its contribution towards economic development, there were also apprehensions about its negative impacts among locals. A stronger resistance to tourist influx into the areas was seen among older residents who feared that their traditional culture and lifestyle would be compromised. Participants also felt that authorities would give greater attention to the needs and wants of the tourists rather than the locals. There is already an increasing "museumification" of the areas where they are preserved to suit the sensibilities of the tourists rather than take into account the needs of the locals. For example, a resident complained that heritage homeowners in Shahjahanabad area cannot make any changes to their houses (such as installation of air conditioners). Due to such restrictions and no positive reinforcement from the authorities, the attitude of locals has changed against heritage and a growing number of residents wanted to get rid of their heritage houses. Such personal problems associated with the heritage nature of the area and thus policies created an animosity and thus further prevented people from enthusiastically and meaningfully participating in heritage and tourism management.

\section{CONCLUSION}

Existing barriers to community participation not only prevent residents from participating in decision making but also discourages them from engaging in any such exercise in the future. This then creates an uncomfortable relationship between local residents and tourism which ultimately leads to animosity towards heritage and conservation activities.

There is an urgent need to work towards meaningful integration of the communities into heritage tourism planning process. First of all, there needs to be an awareness drive to educate the masses about the importance of heritage, impact of tourism and their role in managing their resources. This can be followed by building local citizens networks and groups to engage residents, shopkeepers, traders, NGOs and other relevant stakeholder groups. Such groups would function to strengthen local democracy and allow citizens to voice their opinions. The authorities then shoulder the responsibility to legitimise such local area initiatives and invite them for discussions and deliberations on issues that might affect the locals. There is also a need for confidence building and communication between the governing agencies and local population to assure the latter that their concerns and suggestions would be taken into account. It is only when people start seeing responsive policies and development that they are likely to continue their engagement with policy making.

\section{REFERENCES}

[1] Chan, P.Y., Community participation in heritage management: A case study in Macau, New York. Master's thesis, Columbia University, 2016.

[2] World Travel and Tourism Council, Travel \& Tourism: City Travel and Tourism Impact 2018, London, 2018.

[3] ICOMOS, Heritage as a Driver for Development: Its Contribution to Sustainable Tourism in Contemporary Society, Paris, 2011.

[4] Tosun, C., Expected nature of community participation in tourism development. Tourism Management, 27(3), pp. 493-504, 2006. 
[5] Huibin, X. \& Marzuki, A., Community participation of cultural heritage tourism from innovation system perspective. International Journal of Services Technology and Management, 18(3/4), pp. 105-127, 2012.

[6] Creaco, S., The role of tourism in sustainable economic development, 43rd Congress of the European Regional Science Association, Jyväskylä, Finland, 2003.

[7] World Tourism Organisation and European Travel Commission, City Tourism and Culture - The European Experience, 2005. www.etccorporate.org/resources/uploads/ ETC_CityTourism\&Culture_LR.pdf. Accessed on: 26 Jan. 2020.

[8] UNESCO, 1972. https://whc.unesco.org/archive/convention-en.pdf. Accessed on: 5 Mar. 2020.

[9] Council of Europe, Council of Europe Framework Convention on the Value of Cultural Heritage for Society, Faro, 2005.

[10] Cole, S., Information and empowerment: The keys to achieving sustainable tourism. Journal of Sustainable Tourism, 14(6), pp. 629-644, 2006.

[11] Snyman, S.L., The role of tourism employment in poverty reduction and community perceptions of conservation and tourism in southern Africa. Journal of Sustainable Tourism, 20(3), pp. 395-416, 2012.

[12] Haywood, M., Responsible and responsive tourism planning in the community. Tourism Management, 9(2), pp. 105-118, 1988.

[13] Krippendorf, J., Towards new tourism policies: The importance of environmental and sociocultural factors. Tourism Management, 3(3), pp. 135-148, 1982.

[14] UNCED, Agenda 21, The Rio Declaration on Environment and Development, Rio de Janerio, 1992.

[15] Tosun, C., Limits to community participation in the tourism development process in developing countries. Tourism Management, 21, pp. 613-633, 2000.

[16] Miles, M.B., Qualitative data as an attractive nuisance: The problem of analysis, Administrative Science Quarterly, 24(4), pp. 590-601, 1979.

[17] Chaiklin, H., Doing case study research. American Journal of Dance Therapy, 22, pp. 47-59, 2000.

[18] Flick, U., An Introduction to Qualitative Research, Sage Publications: London, 2009

[19] Glaser, B. \& Strauss, A.L., The Discovery of Grounded Theory: Strategies for Qualitative Research, Aldine: New York, 1967

[20] Aga Khan Development Network, Nizamuddin Urban Renewal Initiative: Annual Report, New Delhi, 2015.

[21] The Economic Times, 2019. https://economictimes.indiatimes.com/news/politics-andnation/tourists-up-at-taj-mahal-and-red-fort-but-qutub-minar-loses-its-no-2-spot/ articleshow/70152555.cms?from=mdr. Accessed on: 20 Dec. 2019.

[22] Shahjahanabad Redevelopment Corporation, Revitalization of Shahjahanabad-Project Concept Proposal, New Delhi, 2014.

[23] Hindustan Times, 2018. www.hindustantimes.com/delhi-news/a-workshop-forheritage-structure-owners-of-shahjahanabad-on-how-to-renovate-properties/story7DzqpH278bsyfNSxT0NdbO.html. Accessed on: 2 Jan. 2020.

[24] Kala, D. \& Bagri, S.C., Barriers to local community participation in tourism development: Evidence from mountainous state Uttarakhand, India. Tourism, 66(3), pp. 318-333, 2018. 